TERCERA PARTE

EDUCACIÓN Y PEDAGOGÍA 



\title{
Uso de la comunicación como método eficaz de prevención ante el VIH: estudio de caso en cinco lugares de alta vulnerabilidad en la ciudad de Bogotá
}

\author{
Jairo Enrique Ordóñez Garzón ${ }^{1}$
}

\section{Introducción}

La idea de intervenir en lugares de sexo anónimo y casual en la ciudad de Bogotá surge debido a las altas tasas de incidencia del $\mathrm{VIH}^{2}$ entre Hombres que tienen Sexo con Hombres HSH, tasas que se incrementan año tras año y que son especialmente altas entre quienes suelen visitar lugares como cuartos oscuros, saunas y vídeos (Ministerio de Salud y Protección Social; Fondo de Población de las Naciones Unidas -UNFPA, 2011).

Al revisar las campañas de prevención del VIH/Sida se observó que eran escasas y no aludían al sexo anónimo y casual entre HSH, uno de los factores de mayor riesgo y una de las poblaciones más afectadas, respectivamente. (Fondo Mundial, 2015).Esta gran carencia llevó a diseñar una estrategia comunicativa que estuviera acompañada de la entrega de condones como mecanismo de prevención ideal no solo del VIH, sino de otras muchas enfermedades de transmisión sexual (como la hepatitis B y C) que pueden agravar y complicar la situación de las personas que ya viven con el VIH (Ministerio de Salud y Protección Social, 2012).

1 Comunicador social de la Universidad Central de Bogotá, Colombia, Doctor en Psicología Social de la Universidad de Konstanz (Alemania) y postdoctor en Educación e Interculturalidad de la Universidad Santo Tomás (Bogotá). Durante los últimos años, ha sido profesor de pregrado y maestría en el área de Comunicación Social. Es experto en el tema de resolución de conflictos, paz y estudios de género. Cuenta con más de quince años de experiencia en el desarrollo de proyectos e investigaciones con empresas privadas, instituciones gubernamentales, organizaciones no gubernamentales, organismos internacionales y entidades académicas. Es autor y coautor de varios libros y artículos sobre la relación entre Comunicación y Conflicto.

2 La prevalencia del VIH entre HSH en Bogotá es de 12,4\%, de acuerdo a un estudio elaborado por la universidad de George Washington en el año 2013 por Zea, Reisen, Poppen y Bianchi. 
La estrategia de comunicación se diseñó partiendo de la selección de sitios que estuvieran diseñados para el sexo casual entre hombres que tienen sexo con hombres (HSH) y que estuvieran dispuestos a colaborar en la promoción del uso del condón. Además, era importante que permitieran el ingreso a los sitios, la observación directa de las interacciones entre las personas, la realización de unas encuestas, la instalación de piezas comunicativas (y su respectivo mantenimiento), la realización de actividades de seguimiento (reuniones, encuestas post, etc.), y el compromiso de suministrar de manera gratuita a los clientes los condones entregados por la Alianza VIH (Organización colombiana dedicada a la prevención del VIH entre poblaciones altamente vulnerables).

En los lugares seleccionados el interés primordial es la consecución de sexo fácil y rápido, por lo que desde un inicio quedó claro que la comunicación debía ser directa, muy concisa, clara, llamativa y sobre todo, no moralizante. Esto constituía un gran reto, pues en Colombia el desarrollo de este tipo de campañas comunicativas ha sido prácticamente nulo: en la revisión de las campañas realizadas no se encontró ninguna realizada para $\mathrm{HSH}$ en lugares de sexo anónimo y casual.

En adición a lo anterior, hay que considerar que toda estrategia de comunicación debe ser concertada para que exista una verdadera apropiación del mensaje y no sea simplemente la emisión de un mensaje que obedece a la lógica e intención exclusiva del emisor. Por tal motivo, una estrategia dirigida a la prevención de la transmisión del VIH y al uso del condón entre hombres que tienen sexo con hombres (HSH) en Bogotá, debió acordarse con aquellos directamente implicados: HSH; instituciones públicas como la Dirección de Diversidad Sexual de la Alcaldía Mayor de Bogotá, organizaciones con experiencia en la población en cuestión (organizaciones no gubernamentales, colectivos, universidades) y por supuesto, los dueños y administradores de establecimientos en los que ocurre el sexo entre hombres, especialmente aquellos en los que este se da de manera más anónima y en condiciones que dificultan el acceso a los preservativos, tales como cuartos oscuros, saunas y videos, entre otros.

\section{Conceptos clave}

\section{HSH}

No todo hombre que tiene sexo con otro hombre se considera gay. En muchas ocasiones esto se debe a una homofobia internalizada que los lleva a rechazar la homosexualidad, incluso la propia. De hecho, varios de los hombres que visitan los lugares de sexo anónimo tienen esposa (Ministerio de Salud y Protección Social; Fondo de Población de las Naciones Unidas -UNFPA, 2011). 
En otros casos, la convivencia forzada entre hombres (como en una cárcel), lleva a que los hombres tengan relaciones sexuales entre sí, sin que necesariamente sean gays o se identifiquen como tales. De igual manera, hay otros casos en los que los hombres son bisexuales, desean experimentar o simplemente tienen un comportamiento sexual que no responde a las categorías existentes. De ahí que en las campañas de prevención para referirse a las relaciones sexuales entre hombres se use la denominación $\mathrm{HSH}$, pues abarca un amplio abanico de posibilidades.

\section{Lugares de sexo anónimo y casual}

Son lugares diseñados para que los HSH se encuentren y tengan el sexo que deseen de manera anónima (penetrativo, oral, grupal, etc.). En la mayoría de estos lugares (saunas ${ }^{3}$, cuartos oscuros ${ }^{4}$, videos ${ }^{5}$ ), hay códigos de vestuario que hacen que los asistentes estén desnudos o semidesnudos. Muchos cuentan con zonas húmedas como piscinas, saunas, jacuzzis y duchas, lo que obliga a las personas a desnudarse, por lo menos, en ciertos momentos, lo que aunado a la oscuridad y a la presencia de material pornográfico como afiches y películas incita a la realización de diversos actos sexuales. Por las características de estos lugares (desnudez, oscuridad, humedad, calor), se hace muy difícil el uso del condón. Por ejemplo, si alguien está en un jacuzzi y se interesa sexualmente por alguien, evidentemente no tiene un condón a la mano, y dada la inmediatez de la satisfacción del deseo que caracteriza a estos lugares, la prevención puede pasar a un segundo plano, en especial, si hay consumo de alcohol y otras sustancias psicoactivas.

\section{Alto grado de vulnerabilidad de los $\mathrm{HSH}$}

Debido a la discriminación, muchas personas se ven obligadas a vivir su sexualidad de manera clandestina y a no preguntar sobre temas que todavía se consideran tabú en nuestra sociedad como el uso del condón, los factores de riesgo asociados al VIH, el sexo oral y el sexo penetrativo entre hombres. Esto es fácilmente evidenciable al ver la carencia en la mayoría de centros de salud, hospitales y clínicas colombianos, de programas de salud diferenciados para hombres que tienen sexo con hombres. Esto lleva a que los integrantes de esta población asuman riesgos

3 Los saunas son lugares que cuentan, generalmente, con cabinas privadas y salas comunes para la proyección de películas pornográficas de HSH. Los asistentes suelen estar desnudos o semidesnudos. Además hay sauna, turco, jacuzzi y otros servicios. El sexo anónimo, casual y con múltiples parejas suele ser la regla.

4 Los cuartos oscuros son lugares sin iluminación y los que allí ingresan (desnudos) pueden tener sexo de manera completamente anónima, ya que nadie puede ver a nadie. La misma oscuridad dificulta el uso del condón y la facilidad de tener acceso a múltiples parejas de manera aleatoria e inmediata aumenta significativamente la ocurrencia de relaciones sexuales riesgosas.

5 Los videos son a espacios donde se presentan películas pornográficas de corte homoerótico. 
muy altos a la hora de tener una vida sexual activa, tales como acudir a lugares en los que es muy difícil acceder a condones como vídeos, cuartos oscuros y saunas, donde por las mismas condiciones físicas, los condones pueden dañarse. La relación entre alta exposición a situaciones de riesgo y exclusión es muy estrecha: .

Los líderes pertenecientes a HSH reportaron como aspectos que los hacían más vulnerables: la homofobia y discriminación por la orientación sexual, en un $80 \%$ de los participantes la vulnerabilidad se relaciona con las prácticas sexuales en medio de la clandestinidad, y un 68\% planteo como importante la alta carencia de espacios públicos y privados para la expresión de la diversidad sexual (Unión Temporal Mecanismo Social en VIH, Cooperative Housing Fundation \& The Global Fund; 2012, p. 283).

Además, en estos lugares se acostumbra el consumo de alcohol y sustancias psicoactivas, que inciden en que se disminuya significativamente la percepción de riesgo, de ahí que sean los HSH la población con mayor prevalencia de $\mathrm{VIH} /$ sida:

En Colombia la epidemia por VIH continua siendo concentrada, es decir, la prevalencia entre hombres que tienen relaciones sexuales con otros hombres (HSH), usuarios de drogas intravenosas y trabajadoras y trabajadores sexuales supera el $5 \%$ y en mujeres gestantes, no es superior al $1 \%$. Se estima que la prevalencia para el año 2009 en el país fue de $0.52 \%$ en la población general, con un cálculo de 122.184 personas con VIH o SIDA en el país (Ministerio de la Protección Social, p. 80, 2010).

Recientes estudios, desde los años 80, Reemplazar lo señalado con: Estudios realizados por diversas entidades como el Fondo Mundial, ONUSIDA y muchas organizaciones nacionales en diversos países muestran que es el mismo estigma social el que lleva a que los HSH no se hagan el test del VIH y por lo mismo hay muchos HSH que son seropositivos, pero no lo saben, lo cual hace que sean multiplicadores potenciales del virus, lo que aunado a las barreras del sistema de salud, los hace aún más vulnerables, lo que aunado a la ausencia de programas de salud con enfoque diferencial para poblaciones vulnerables y sexualmente diversas, tanto en lo pertinente a la prevención como a los tratamientos, hace que los HSH sean altamente vulnerables y estigmatizados

En este estudio se pretendió indagar sobre los determinantes sociales que hacen vulnerables a los hombres que tienen sexo con hombres en la ciudad de Bogotá. Se sabe que la estigmatización de la sexualidad, especialmente de la homosexualidad, se nutre de la invisibilidad social en la que se la ha ubicado históricamente, y a su vez contribuye a perpetuarla. El pertenecer a grupos marginales, sin acceso a la información y con discriminación social, hace que los hombres que tienen sexo con hombres sean más vulnerables; por no tener la posibilidad de ingresar a los programas eficaces de tratamiento y prevención 
para su protección personal, ni el acceso adecuado y oportuno a los servicios de salud (Unión Temporal Mecanismo Social en VIH, Cooperative Housing Foundation \& The Global Fund; 2012, p. 26).

A lo anterior hay que agregar que en los sitios para encuentros sexuales casuales muchas veces no hay un acceso fácil a condones y lubricantes, tal vez por desinterés de los dueños que consideran que vender o suministrar condones no es su negocio ni su misión, relegando dicha responsabilidad enteramente en los clientes, quienes en muchas situaciones se dejan llevar por la situación, además aunque quieran, muchas veces es imposible portar un condón si se está desnudo o semidesnudo. En estos lugares, muchas veces, la prevención es dejada de lado en aras de "aprovechar" la oportunidad de tener una o varias relaciones sexuales de manera fácil e inmediata.

En este contexto, el presente trabajo de intervención se plantea como un pilotaje para el desarrollo de una estrategia comunicativa a gran escala en Bogotá e incluso a nivel nacional con enfoque diferencial en HSH que acuden a lugares de sexo anónimo y casual.

\section{Bareback y serosorting}

Una campaña enfocada en la prevención del VIH y el uso del condón no puede dejar de considerar dos modalidades de sexo que se oponen al sexo seguro y que cada día cuentan con más adeptos, además de que prácticamente se originaron en comunidades de HSH. La primera es el bareback que consiste en tener a propósito sexo penetrativo sin el uso del condón, y el serosorting, que básicamente consiste en que los portadores del VIH tienen sexo entre sí sin condón y los no portadores, a su vez, tienen sexo sin condón, sOlo con no portadores del VIH.

A los practicantes del bareback les excita el sexo sin protección y lo consideran una decisión sobre su cuerpo que solo les incumbe a ellos, lo que lo convierte, incluso, en una acción política:

Las posiciones a favor del bareback son varias, por ejemplo: que en una relación estable el no usar preservativo es una conducta que permite un acercamiento afectivo con el compañero y expresa confianza mutua, además que dar y/o recibir semen es percibido psicológicamente por algunos como algo necesario y profundo. Otra poderosa razón es la importancia y necesidad de sentir el cuerpo como propio y en sintonía con sus sensaciones y placeres, no como un objeto en el que se naturalizan e instrumentalizan políticas públicas en salud, una especie de militancia de la autonomía del cuerpo desde la resistencia. También se argumenta como válida la posibilidad que el bareback satisfaga el deseo de sentir peligro y riesgo, incluso como parte de un estilo de vida que les produce placer. Otros lo hacen para cumplir la fantasía de seroconvertir a otro (infectarlo con VIH), o por la sola pretensión de detener el "cansancio" del cuidado crónico (fatiga al condón le llaman 
algunos). Finalmente el sentido de pertenencia a una comunidad (la de los barebackers) ha sido también invocado como defensa de esta práctica sexual. (Anodis, 2008, pp. 1-2).

En cuanto al serosorting, obviamente las personas pueden mentir sobre su estado o sencillamente estar en el periodo de ventana, aquel en el que el cuerpo no ha desarrollado anticuerpos y el virus resulta indetectable, de ahí que el serosorting sea una práctica tan riesgosa como el bareback, y para aquellos que están infectados por VIH los riesgos pueden ser la adquisición de otras enfermedades de transmisión sexual, el aumento de su carga viral y/o la reinfección con una nueva cepa de virus resistente a los medicamentos.

Valga la pena aclarar que el estado colombiano penaliza a quienes infecten deliberadamente con el virus del VIH a otra persona, pero obviamente la ley no es suficiente para eliminar estas prácticas sexuales, ellas perdurarán porque cada individuo tiene el derecho a decidir sobre su propia vida:

Nosotros sostenemos dos cosas que parecen estar en contradicción. Primero, todo individuo tiene plena libertad para disponer de su propio cuerpo. Si yo me quiero inyectar el virus del VIH/Sida, tengo la libertad para hacerlo. Mi relación con mi propio cuerpo no es negociable con nadie. Segundo, institucionalmente nosotros hacemos campañas de prevención de lucha contra el Sida. Nuestra postura es de promoción de la salud, del cuidado del propio cuerpo, de la práctica del sexo seguro. Creemos que una persona se tiene que cuidar, tiene que estar saludable, pero no podemos obligar a nadie para hacerlo (Anodis, 2008, p. 3).

Por tal motivo se sugiere incluir en futuras campañas ${ }^{6}$, los temas del bareback y del serosorting, indicando los riesgos que tienen, las ventajas de abandonar dichos comportamientos, pero también dando alternativas a quienes quieren seguir con ellas y sugiriéndoles prácticas que disminuyan los riesgos asociados, tales como disminuir el número de parejas y evitar al máximo el contacto con los fluidos corporales, de esta manera se evita que sus practicantes rechacen de plano las campañas de prevención.

\section{Reinfección y coinfección}

La reinfección se refiere a infectarse con VIH viviendo ya con VIH, lo que hace que el organismo deba combatir dos tipos de virus. En algunos casos la reinfección puede darse con cepas agresivas y/o resistentes a los medicamentos.

Por su parte, la co-infección se da cuando viviendo con el VIH se adquiere otra

6 A petición de la Alianza VIH, el presente trabajo se enfocó únicamente en incentivar el uso del condón, pero no en mencionar temas como el bareback o el serosorting. 
infección como la hepatitis B o C, lo cual puede causar serias complicaciones médicas y deteriorar severamente la calidad de vida de las personas

\section{Objetivos}

- Contribuir a la disminución del riesgo de transmisión del VIH entre HSH en 5 lugares de Bogotá.

- Facilitar el acceso a los condones donde ocurre sexo casual y anónimo.

- Incentivar el uso del condón entre los HSH que acuden a los lugares seleccionados donde ocurre sexo casual y anónimo.

\section{Método}

- Enfoque: mixto. Para recolectar información se usaron herramientas como grupos focales y encuestas, también entrevistas en profundidad con los dueños y administradores de los lugares, y observación etnográfica de cada uno de los lugares. Luego se trianguló la información.

- Alcance: correlacional. Se busca incidir en las variables: Uso del condón entre HSH que acuden a lugares donde ocurre sexo casual y anónimo (saunas, cuartos oscuros y videos).

- Periodo: la presente investigación se desarrolló entre noviembre de 2012 y septiembre de 2013.

\section{Estrategias e intervenciones}

1. Entrevistas a los dueños y/o administradores de los lugares seleccionados.

2. Encuestas a los HSH que acuden a los lugares seleccionados en lo pertinente al uso del condón.

3. Realización de una etnografía, incluyendo una etnografía visual, de los establecimientos seleccionados tanto por el número de hombres que los visitan, como por ofrecer precarias condiciones para la práctica del sexo seguro.

4. Caracterización de cada uno de los lugares seleccionados.

5. Diseño de varios productos comunicativos.

6. Validación de los productos comunicativos con HSH, dueños y/o administradores de los lugares seleccionados. Se involucró a los dueños y administradores para que vieran en la campaña una mejora para sus sitios al poder ofrecerlos como espacios seguros. La propuesta que se les hizo 
a los establecimientos consistió en que ellos financiarían parcialmente los productos (manillas, avisos, cajas, dispensadores, etc.), los cuales llevarían el logo y nombre del establecimiento respectivo. A cambio, la Alianza VIH Bogotá los surtiría gratuitamente de condones, bajo la condición de no venderlos.

7. Ajuste de los productos de acuerdo a la validación.

8. Entrega e instalación de las piezas comunicativas.

9. Medición del impacto de la estrategia comunicativa.

\section{Resultados}

\section{Selección de lugares y diseño de las piezas comunicativas}

Luego de visitar varios lugares de sexo anónimo y casual, se seleccionaron cinco sitios que cumplían con los requisitos necesarios, como se observa en la tabla 1:

Tabla 1. Lugares seleccionados para implementar la estrategia comunicativa de prevención del VIH.

\begin{tabular}{|l|l|l|}
\hline \multicolumn{1}{|c|}{ Establecimiento } & \multicolumn{1}{c|}{ Tipo de lugar } & \multicolumn{1}{c|}{ Localidad } \\
\hline Cómplices & Sauna y Video & Santafé \\
\hline DARK CLUB & Video y Hard Sex & Chapinero \\
\hline St Moritz & Sauna & Chapinero \\
\hline Casa Romana & Sauna y Video & Santafé \\
\hline Acuario's Spa & Sauna & Kennedy \\
\hline
\end{tabular}

Fuente: elaboración propia.

Luego de sistematizar la información recolectada en cada sitio a través de entrevistas y encuestas, se hizo un diseño preliminar de cada una de las piezas comunicativas para desarrollar una campaña de promoción del uso del condón y de prevención del VIH/Sida, apoyándose también en campañas realizadas en otros países y en la literatura científica sobre el tema. Con estos diseños preliminares se procedió a realizar una serie de validaciones con dueños y administradores de establecimientos, con $\mathrm{HSH}$, con usuarios de los establecimientos, con miembros de la Alianza VIH Bogotá, y personas con VIH. Tras las validaciones se obtuvieron las siguientes piezas comunicativas: 
Tabla 2. Piezas comunicativas

\begin{tabular}{|l|l|l|}
\hline \multicolumn{1}{|c|}{ Tipo de pieza } & \multicolumn{1}{|c|}{ Diseño inicial } & \multicolumn{1}{c|}{ Diseño final } \\
\hline $\begin{array}{l}\text { Guía de prevención sobre } \\
\text { VIH/Sida para HSH }\end{array}$ & $\begin{array}{l}\text { Textos de carácter científico e } \\
\text { imágenes explícitas }\end{array}$ & $\begin{array}{l}\text { Textos cortos, basados en } \\
\text { información científica, pero } \\
\text { escritos en lenguaje coloquial. } \\
\text { Se conservaron las imágenes } \\
\text { explícitas con algunos ajustes }\end{array}$ \\
\hline Portacondón personal & $\begin{array}{l}\text { Manilla para ser usada en la } \\
\text { muñeca }\end{array}$ & $\begin{array}{l}\text { Portacondón que puede ser } \\
\text { usado en el tobillo o muñeca }\end{array}$ \\
\hline Avisos fotoluminosos & $\begin{array}{l}\text { Mensaje concreto e imágenes } \\
\text { explícitas }\end{array}$ & $\begin{array}{l}\text { Mensajes concretos en un } \\
\text { lenguaje muy coloquial e } \\
\text { imágenes explícitas }\end{array}$ \\
\hline Dispensador de condones & $\begin{array}{l}\text { Parecido a un buzón de } \\
\text { sugerencias }\end{array}$ & $\begin{array}{l}\text { Se le dio una forma fálica (de } \\
\text { color rojizo y cilíndrica) }\end{array}$ \\
\hline Eslogan & $\begin{array}{l}\text { Si te seduce la pasión, iponte el } \\
\text { condón! }\end{array}$ & $\begin{array}{l}\text { Si te seduce la pasión, iponte el } \\
\text { condón! }\end{array}$ \\
\hline Logo & $\begin{array}{l}\text { Destaca el logo y el Eslogan } \\
\text { de la campaña: Si te seduce la } \\
\text { pasión, iponte el condón! }\end{array}$ & $\begin{array}{l}\text { Se rediseñó el logo para } \\
\text { hacerlo más fálico, claro y } \\
\text { notorio }\end{array}$ \\
\hline Afiches & \multicolumn{2}{|l|}{ cambios } \\
\hline
\end{tabular}

Fuente: elaboración propia.

De igual forma se definió el uso y objetivo de cada elemento, como se explica en seguida:

- Guía de Prevención de VIH/sida para HSH. Es un documento explícito, muy visual y con información clave y concisa sobre el VIH/Sida y los $\mathrm{HSH}$. Se responde a preguntas realtivas a la protección que brinda la circuncisión, los riesgos del sexo oral y anal, la importancia de usar condón aun con cargas virales indetectables y terapias antirretrovirales exitosas. También se mencionan algunos comportamientos de reducción de riesgo a tener en cuenta en los saunas, cuartos oscuros y videos, y se brinda información esencial como dónde conseguir más información o dónde acudir en caso de haber tenido una situación de riesgo de infección.

Uso: está diseñada para los saunas y videos seleccionados, ya que se enfoca en el tema del sexo entre HSH de manera explícita. Las imágenes sugerentes van en concordancia con la estética de los saunas, cuartos oscuros y videos: alusión al sexo entre HSH, nudismo y énfasis en la sensualidad masculina. 
Objetivo: orientar con preguntas clave, para tratar de evitar conductas de riesgo para $\mathrm{VIH} /$ sida.

- Portacondones individuales: diseñados como tobilleras con el fin de que todo el tiempo de estadía en los saunas, cuartos oscuros y videos, los HSH puedan siempre tener un condón a la mano. Además tienen un mensaje: Uso Condón, Lo Tengo a la Mano. Disponibles en colores rojo, verde y azul, muy llamativas para que además de prácticas sean estéticas y las personas se animen a usarlas. También permiten ser usadas como llavero para cargar las llaves de los casilleros donde se dejan la ropa y los objetos personales.

Uso: su principal fin es el de permitir a los HSH siempre tener acceso a un condón, el cual va debidamente asegurado para evitar daños en el mismo. Se puede llevar como tobillera o en el antebrazo o incluso en la muñeca. De esta forma se asegura que las personas siempre tengan acceso a un condón, independientemente de si están desnudas o semidesnudas, o en una zona oscura o iluminada, de igual manera se puede llevar a zonas con alto grado de humedad como turcos o saunas por periodos cortos.

Objetivo: asegurar el acceso a los condones en todo momento y lugar.

- Avisos fotoluminosos: se diseñaron tres, uno alusivo al sexo oral, uno al sexo anal y otro a los besos y caricias. Todos con imágenes muy explícitas y diseñados con el fin de que en las zonas en los que los HSH tienen sexo haya un aviso que recuerde el uso del condón. En los lugares seleccionados el sexo ocurre en sitios oscuros o semioscuros, por lo que un aviso fotoluminoso permite llegar con el mensaje de la campaña en el momento en que se tienen relaciones sexuales y en el que es más importante enfatizar el uso del condón, sin que ello altere el ambiente de oscuridad que facilita los encuentros sexuales; los avisos dejan leer el mensaje, pero no iluminan.

Los avisos están hechos de un material que permite ubicarlos en zonas húmedas como saunas y turcos, lo que garantiza, que sin importar el lugar, el aviso se podrá instalar y el mensaje llegará en el momento oportuno: aquel en el que se decide tener sexo anónimo.

Uso: se diseñaron para ser instalados en donde los HSH tienen sexo: cuartos oscuros, saunas, turcos, laberintos, entre otros, independientemente del grado de luz o de humedad.

Objetivo: recordar a los HSH el uso del condón durante sus prácticas sexuales y en los sitios donde ellas tienen lugar.

- Dispensador de condones. Tiene un mensaje: “¡Ponte el condón, llévalo siempre!” Tiene, además, una forma fálica y es de color rojizo, como todos los elementos está enfocado en las relaciones sexuales. 
Uso: se diseñó para ser colocado en las zonas donde sucede el sexo entre $\mathrm{HSH}$, su función primordial es el suministro de condones previo a las relaciones sexuales. Es además un complemento a los portacondones individuales (tobilleras), las cuales tienen capacidad para un condón. La idea es que al usar el condón del portacondón, la persona pueda fácilmente encontrar un dispensador y "recargarlo" o simplemente tomar un condón cuando desee, sin necesidad de acudir a la recepción o sin tener que buscar dinero.

Objetivo: facilitar el acceso a los condones.

- Eslogan: acompaña varias de las piezas, es una frase de identificación, de fácil recordación y que contiene el mensaje esencial de usar condón: "Si te seduce la pasión, iponte el condón!".

Uso: en los afiches, en el folleto y en los avisos fotoluminosos

Objetivo: resumir en una frase el principal objetivo de la campaña

- Logo: es la imagen que identifica a la campaña y reafirma el mensaje de usar condón, está hecho a manera de señal de tránsito.

Uso: está presente en todos los productos de la campaña, menos en el portacondón (por espacio, no se pudo incluir).

Objetivo: lograr identificación y recordación en el grupo objetivo

- Afiches de dos hombres besándose. Tiene el eslogan de la campaña: Si te seduce la pasión, iponte el condón! A continuación se indica que: $E l$ condón es el método más eficaz para evitar infecciones de transmisión sexual como el VIH/sida. Y termina con los datos de la Liga Colombiana de Lucha contra el Sida, para quien le interese conocer más sobre el VIH/sida o para quien quiera saber qué hacer después de haber tenido una situación de riesgo.

Uso: para todo tipo de zonas sociales, especialmente en los bares de los lugares seleccionados; también se puede usar en cualquier lugar de homosocialización.

Objetivo: llamar la atención sobre el sexo entre HSH y la importancia de usar condón siempre.

\section{Entrega de piezas y uso del condón}

Luego de la etapa del diseño y realización, vino la etapa de la entrega y montaje en cada uno de los lugares seleccionados. Cada una de las piezas se ubicó de acuerdo al uso y el objetivo que le correspondió. El proceso de instalación se hizo conjuntamente con los dueños y/o administradores de los locales, quienes se comprometieron a hacer un uso adecuado de las mismas, a entregar los condones de manera gratuita y mantener en buen estado cada una de las piezas. Para ello, se firmó una carta de compromiso. 
Con el fin de hacer seguimiento al impacto de la campaña de prevención se realizaron visitas a los lugares seleccionados y se llevaron a cabo reuniones con los dueños y/o administradores de los lugares con el fin de monitorear través de las entrevistas y la observación directa el uso que se hace de cada una de las piezas. Para complementar las observaciones y entrevistas se realizó un monitoreo del indicador clave de la campaña, el autoreporte del uso del condón, para lo cual se aplicó seis meses después de iniciada la estrategia una encuesta para los clientes:

Tabla 3. HSH que prefieren el sexo sin condón

\begin{tabular}{|l|l|l|}
\hline \multicolumn{1}{|c|}{ Establecimiento } & $\begin{array}{c}\text { \% de encuestados que dicen } \\
\text { no usar condón o preferir el } \\
\text { sexo sin condón } \\
\text { (antes de la campaña) }\end{array}$ & $\begin{array}{c}\text { \% de encuestados que dicen } \\
\text { no usar condón o preferir el } \\
\text { sexo sin condón } \\
\text { (después de la campaña) }\end{array}$ \\
\hline Cómplices & $20 \%$ & $15 \%$ \\
\hline DARK CLUB & $30 \%$ & $25 \%$ \\
\hline St. Moritz & $20 \%$ & $14 \%$ \\
\hline Casa Romana & $10 \%$ & $7 \%$ \\
\hline Acuario's $\mathrm{Spa}^{1}$ & $15 \%$ & $10 \%$ \\
\hline
\end{tabular}

Fuente: elaboración propia.

En cuanto a las piezas comunicativas realizadas, se obtuvieron los siguientes resultados, basados en los autoreportes de los HSH, administradores, dueños y trabajadores de los saunas, videos y cuartos oscuros:

Tabla 4. Impacto de las piezas comunicativas

\begin{tabular}{|l|l|l|}
\hline \multicolumn{1}{|c|}{ Pieza } & \multicolumn{1}{c|}{ Impacto } & Media-baja \\
\hline $\begin{array}{l}\text { Guía de prevención sobre } \\
\text { VIH/Sida para HSH }\end{array}$ & Medio-bajo \\
\hline Portacondón personal & Alto & Alta \\
\hline Avisos fotoluminosos & Medio & Media \\
\hline Dispensador de condones & Alto & Alta \\
\hline Eslogan & Medio & Media \\
\hline Logo & Medio & Media \\
\hline Afiches & Medio & Media \\
\hline
\end{tabular}

Fuente: elaboración propia.

A pesar de ser compacta (cabe en un bolsillo) y de contener información útil y práctica, la guía de prevención fue el material que tuvo menos impacto y que resultó menos efectivo para incentivar el uso del condón. Es claro que en los lugares seleccionados las personas no quieren material de este tipo, ni quieren leer nada, 
por muy relevante que pueda ser. Sin embargo, esta guía ha tenido mayor aceptación en otros escenarios como bares y talleres.

De acuerdo con los encuestados, las piezas de mayor impacto y efectividad resultaron ser los portacondones y los dispensadores, ya que permitieron que los HSH accedieran fácilmente a los preservativos sin importar el lugar y sin necesidad de ir a buscarlos o tener que pagar dinero por ellos. Por eso, estas dos piezas se destacan como logros importantes de la campaña, pues permitieron lograr el objetivo de aumentar el uso del condón.

En cuanto a las demás piezas, afiches, logo, eslogan y avisos, las personas reportaron que los habían leído y visto, que eran llamativos, pero no destacaban especialmente en el lugar, donde era más notoria la presencia de monitores de TV. Se confirma, entonces, que todo afiche o aviso resulta accesorio, aunque pueden ser útiles si logran masificarse (al ubicarse en muchos lugares), para que el eslogan y el logo logren recordación y con ellos llegue el mensaje básico de la campaña.

\section{Réplicas en otras ciudades}

Basado en los logros del presente trabajo, el Fondo Mundial de las Poblaciones (Seccional Colombia), realizó a finales del 2014 un gran tiraje de los afiches y de la guía de prevención, con el fin de distribuirlos en diferentes talleres y en lugares de sexo anónimo y casual para HSH en toda Colombia. Estas acciones se ejecutaron con el apoyo de la Corporación Red Somos y se está trabajando en el desarrollo de una estrategia y en la consecución de fondos que permitan continuar con las campañas de prevención y medir el impacto de los productos realizados en ciudades diferentes a Bogotá (Corporación Red Somos, 2016).

\section{Conclusiones y retos}

Se logró bajar en 5 puntos porcentuales el número de personas que indicaron la preferencia del sexo sin condón: en un inicio este indicador ponderado era de $19 \%$, y luego de la campaña fue de $14 \%$. Sin embargo, este indicador pudo ser mucho mayor. Pero debido a algunos trámites administrativos y presupuestarios de la Alianza VIH, el seguimiento no se realizó como estaba planeado. Además, en algunas ocasiones se presentaron demoras en los suministros de condones, lo que desmotivó a los dueños. Adicionalmente, se observó que el portacondón personal necesita un rediseño, pues el material usado se desgastó muy rápido. Hasta el momento está pendiente una segunda fase que complemente y desarrolle los hallazgos del presente pilotaje.

Dado el alto porcentaje de personas que prefieren el bareback o sexo sin condón en los lugares seleccionados para la presente campaña (varía entre 8 y $25 \%$ dependiendo del lugar), es importante que se considere este tema dentro de las acciones de prevención a futuro, en especial porque en Colombia no se ha diseñado 
una estrategia de prevención que hable del bareback, el serosorting o el cruising. Podrían explorarse en próximas intervenciones, teniendo en cuenta que lo aquí presentado es apenas un primer paso en la prevención del VIH entre HSH que practican el sexo anónimo y casual.

Además, estas prácticas deben incluirse en todas las campañas de prevención porque están correlacionadas con la reinfección y la co-infección. La reinfección se refiere a infectarse con VIH viviendo ya con VIH, lo que hace que el organismo deba combatir dos tipos de virus. En algunos casos la reinfección puede darse con cepas agresivas y/o resistentes a los medicamentos.

Por su parte, la co-infección se da cuando viviendo con el VIH se adquiere otra infección como la hepatitis B o C, lo cual puede causar serias complicaciones médicas y deteriorar severamente la calidad de vida de las personas. Acato la sugerencia. Ya se incluyeron en la sección de conceptos clave.

Por lo anterior, una guía sobre bareback y serosorting es fundamental, particularmente teniendo en cuenta la deficiente educación sexual de los colombianos en general, y en particular de los HSH, para quienes no ha habido una educación con enfoque diferencial, como lo evidencia el hecho de que en varios talleres, muchos HSH no saben ni siquiera lo que es circuncisión.

En adición a lo anterior, es importante recarlcar que las campañas de prevención del VIH/sida entre HSH deben enfocarse en lugares de sexo casual, ya que es allí donde se concentra el sexo sin protección entre HSH. No obstante, hay muchos lugares de sexo casual que no están formalmente establecidos como los videos, saunas o cuartos oscuros; muchos de ellos son lugares de acceso público que durante muchos años han servido para sexo casual entre HSH y que a pesar de sus inicios como lugares de homosocialización en épocas en que se penalizaba legalmente el sexo entre hombres, hoy en día siguen siendo lugares de prácticas sexuales entre HSH y justamente por su carácter de lugares de actividad sexual clandestina no hay ningún mensaje de prevención y ninguna disponibilidad de condones, salvo los que cada persona lleva, de ser así.

Además, las cuestiones de seguridad dificultan el acceso de las campañas y de poder negociar el uso del condón, pues en estos lugares por su soledad, relativo aislamiento y oscuridad, es fácil que una persona sea coaccionada a no usar condón o que incluso sea forzada a tener prácticas sexuales sin que las víctimas denuncien por temor a que sus prácticas sexuales se hagan públicas o por el escarnio público debido a la cultura machista que no tolera ni concibe que un hombre pueda ser violado:

Generalmente, la sociedad identifica la violación con la agresión sexual hacia una mujer, lo que hace que los casos en los que los hombres son las víctimas queden ocultos. 
A ello, se suma la vergüenza que supone para muchos hombres reconocer la agresión, por lo que las estadísticas no reflejan la mayoría de los casos que quedan escondidos para siempre en la mente de las víctimas. (The Prisma, 2012).

En varios países se han intentado campañas de prevención sexual en zonas de cruising que se centran en las características de las prácticas sexuales que allí ocurren: son rápidas, se suelen tener múltiples parejas y no se conciben cuerpos como tal, sino partes de cuerpos que se consideran únicamente en la medida en que pueden satisfacer un deseo sexual, es decir, una cosificación del otro que incide en la disminución de la percepción del riesgo al no reconocer al otro como sujeto, sino como un objeto para usar y desechar. Por esto, una campaña de prevención diseñada para lugares de cruising debe tener en cuenta las especificidades de este. Un ejemplo a seguir es el caso de Holanda que cuenta con protocolos para estas zonas, y ha designado y equipado lugares donde se permite el cruising colocando preservativos dentro de los árboles, entre otras acciones (Martin et ál., 2008).

\section{Puntos de discusión}

Los siguientes ítems son elementos a tener en cuenta para que otros investigadores continúen con el tema aquí presentado o alguno derivado del mismo que sea de su interés. De igual manera, sirven para sugerir posibles líneas de trabajo en el campo de la prevención del VIH entre HSH y en lugares de alta vulnerabilidad.

- El índice de hombres que prefieren el sexo sin condón, después de la campaña, en los lugares seleccionados sigue siendo muy alto ( $14 \%$ en promedio), sobre todo teniendo en cuenta que los HSH suelen tener varias parejas sexuales en cada visita a los lugares de sexo anónimo y casual, lo que potencialmente puede significar un gran número de personas infectadas cada año. Estas prácticas dan pie a un círculo vicioso en el que cada nuevo infectado potencialmente puede infectar a muchos otros. También llama la atención que tantas personas no usen condón, siendo este el foco de todas las campañas de prevención del VIH. Por eso se debe trabajar más de cerca con los HSH que practican el bareback y el serosorting para ver qué factores están incidiendo para que no usen condón.

- Todos los dueños y administradores concuerdan en que el bareback es una práctica recurrente en sus locales y que primordialmente se da por una cuestión de gusto, independientemente del costo de los condones o de la disponibilidad de los mismos.

- Es muy importante realizar campañas educativas sobre el bareback y 
el serosorting, ya que parece existir mucha desinformación sobre estas prácticas y los riesgos que conllevan.

- Es importante disminuir los riesgos asociados al cruising en lugares públicos, una práctica muy arraigada entre los HSH y que por su clandestinidad y aislamiento es de muy alto riesgo.

- Para el éxito de las campañas de prevención es muy importante que exista continuidad, tanto de los mensajes y de las piezas comunicativas, como de la distribución gratuita de condones, para evitar que las intervenciones se conviertan en actividades aisladas y desconectadas. Valga la pena recordar que aunque no lo cumplen, las EPS por obligación deben suministrar condones gratuitamente a sus afiliados, tal y como lo dice el artículo segundo del acuerdo 380 de 2007, en el que se establece:

- Incluir en el Plan Obligatorio de Salud(POS) del Régimen Contributivo y del Régimen Subsidiado el suministro del condón masculino de látex en condiciones de calidad media y tecnología apropiada disponible en el país, el cual se financiará con cargo a la UPC vigente tanto del Régimen Contributivo como del Subsidiado. Esta inclusión se hará efectiva una vez se cuente con la reglamentación que expida el Ministerio de la Protección Social para el suministro del mismo, desde la perspectiva de Salud Pública y de la racionalidad administrativa y científica (Ministerio de la Protección Social).

- Se recomienda que a la hora de hablar de sexo seguro se incluyan prácticas como el rimming, el fisting, el pissing, los glory holes y otras, las cuales si bien son de bajo riesgo para VIH, sí son de alto riesgo para otras infecciones como hepatitis $\mathrm{B}$, lo cual podría causar una co-infección.

\section{Referencias}

American Infobae (5 de octubre de 2012). En Canadá ya no es delito ocultar ser seropositivo. Sección: Sociedad.

Anodis (5 de febrero de 2008). El sexo en los Tiempos Modernos: El Bareback y el Serosorting. Buenos Aires: Autor.

Brehm, S, Kassin, S y Fein, S.(2005). Social Psychology. Boston: Houghton Mifflin.

Ministerio de la Protección Social. Acuerdo 380 de 2007. Bogotá: Autor

Corporación Red Somos. (2016). Sección Proyectos, página institucional: redsomos.org

De Benito, E. (27 de agosto de 2010). Dos no se infectan si uno no quiere. El País,Sección Sociedad. 
Fondo Mundial. (2015). Consideraciones sobre el Trabajo Sexual, HSH y Personas Transgénero en el contexto de la epidemia de VIH. Nota Informativa. Bogotá: Autor.

Martín, M., Rojas, D., Martínez, J., Sánchez, J., Remor, E., \& Del Romero, J. (2008). La prevención del VIH/SIDA en el colectivo de hombres que mantienen relaciones sexuales con hombres (HSH). Ejemplos de intervenciones preventivas, individuales, grupales y comunitarias. Ciencia y Salud. (19) 2. ISSN: 1135- 0806

Ministerio de Salud y Protección Social (2010). Base de datos del Observatorio Nacional de Gestión de VIH/SIDA. Bogotá: Autor.

Ministerio de Salud y Protección Social; Fondo de Población de las Naciones Unidas [UNFPA] (2011). Estudio Sobre Comportamiento Sexual y Prevalencia de VIH en Hombres que tienen Relaciones Sexuales con Hombres en Siete Ciudades de Colombia. Bogotá: Legis.

Ministerio de Salud y Protección Social; Fondo de Población de las Naciones Unidas [UNFPA] (2012). Informe mundial de avances en la lucha contra el Sida. Colombia 2012. Bogotá: Autor.

Organización Mundial de la Salud (2012). Prevención y tratamiento de la infección por el VIH y otras infecciones de transmisión sexual entre hombres que tienen sexo con hombres y personas transgénero: recomendaciones para un enfoque de salud pública. Washington, D.C.: Organización Panamericana de la Salud.

The Prisma (13 de mayo de 2012). El Silencio del Hombre Violado. Sección: Derechos Humanos.

Unión Temporal Mecanismo Social en VIH; Cooperative Housing Foundation y The Global Fund (2012). Estudio de la Oferta, capacidad y necesidades de servicios comunitarios y redes sociales para el trabajo en promoción y prevención, servicios de salud y redes de prestación de servicios para la atención integral del VIH y georeferenciación de grupos priorizados para Colombia. Bogotá: Alcaldía Distrital.

Zea, M., Reisen, C., Poppen, P. y Bianchi, F. (2013). Prevalencia del VIH, Comportamiento Sexual y Circunsición en Hombres que tienen Sexo con Hombres, en Bogotá. Washington: George Washington University. 
Anexo 1. Portada de la Guía de Prevención (con el logo y el eslogan de la campaña)

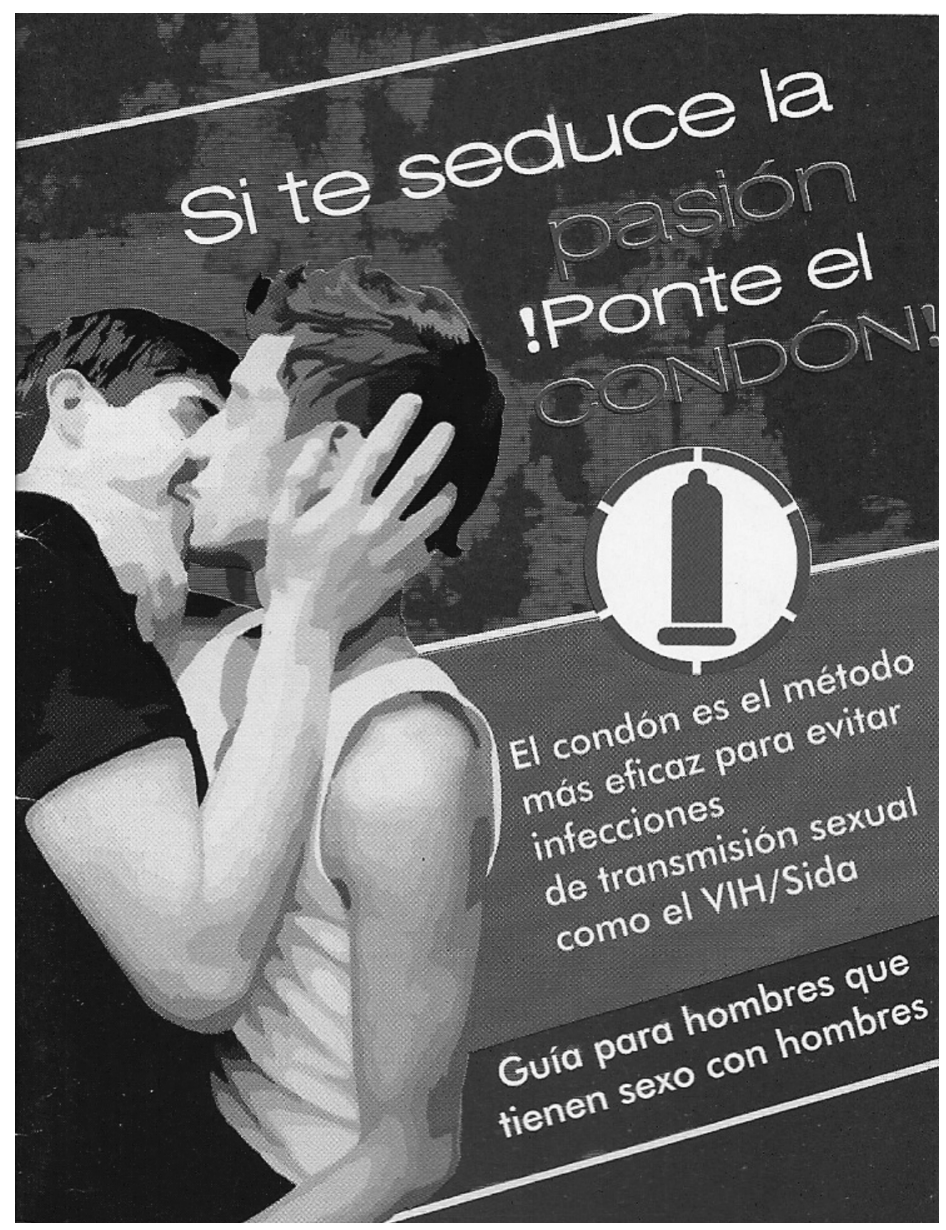

Fuente: elaboración propia. 
Anexo 2. Diseño del portacondón personal

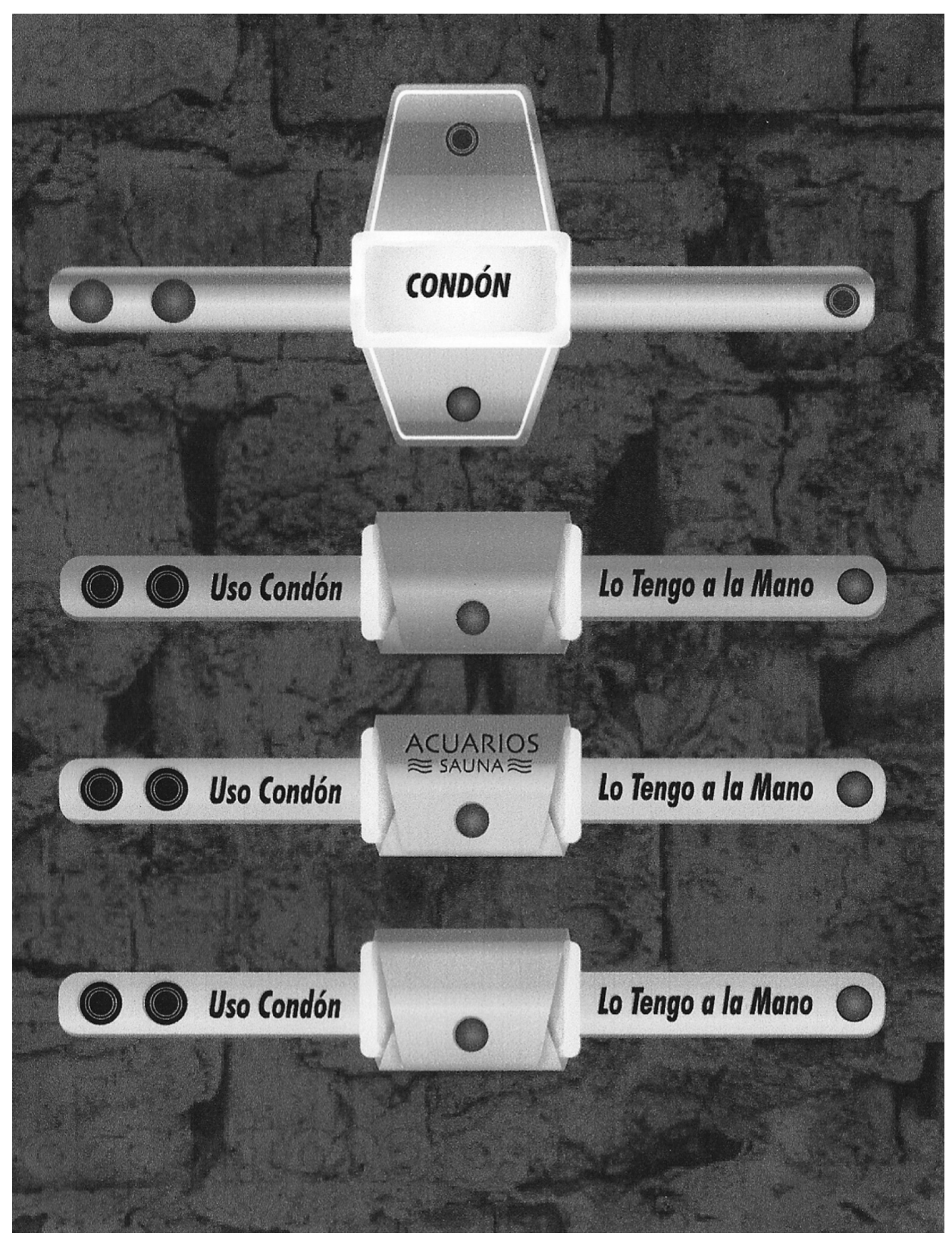

Fuente: elaboración propia. 
